\title{
LIVER
}

\section{Expression of insulin-like growth factor I by activated hepatic stellate cells reduces fibrogenesis and enhances regeneration after liver injury}

\author{
S Sanz, J B Pucilowska, S Liu, C M Rodríguez-Ortigosa, P K Lund, D A Brenner, C R Fuller, \\ J G Simmons, A Pardo, M-L Martínez-Chantar, J A Fagin, J Prieto
}

Gut 2005;54:134-141. doi: 10.1136/gut.2003.024505

See end of article for authors' affiliations

\section{Correspondence to:} Professor J Prieto, Division of Hepatology and Gene Therapy, Clinica

Universitaria and Medical School, Center for Applied Medical Research (CIMA), University of Navarra, 31008, Pamplona, Spain; jprieto@unav.es

Accepted for publication 25 May 2004
Background/Aim: Hepatic stellate cells (HSCs) express $\alpha$-smooth muscle actin ( $\alpha S M A)$ and acquire a profibrogenic phenotype upon activation by noxious stimuli. Insulin-like growth I (IGF-I) has been shown to stimulate HSCs proliferation in vitro, but it has been reported to reduce liver damage and fibrogenesis when given to cirrhotic rats.

Methods: The authors used transgenic mice (SMP8-IGF-I) expressing IGF-I under control of aSMA promoter to study the influence of IGF-I synthesised by activated HSCs on the recovery from liver injury. Results: The transgene was expressed by HSCs from SMP8-IGF-I mice upon activation in culture and in the livers of these animals after $\mathrm{CCl}_{4}$ challenge. Twenty four hours after administration of $\mathrm{CCl}_{4}$ both transgenic and wild type mice showed similar extensive necrosis and increased levels of serum transaminases. However at 72 hours SMP8-IGF-I mice exhibited lower serum transaminases, reduced hepatic expression of $\alpha \mathrm{SMA}$, and improved liver morphology compared with wild type littermates. Remarkably, at this time all eight $\mathrm{CCl}_{4}$ treated wild type mice manifested histological signs of liver necrosis that was severe in six of them, while six out of eight transgenic animals had virtually no necrosis. In SMP8-IGF-I mice robust DNA synthesis occurred earlier than in wild type animals and this was associated with enhanced production of HGF and lower TGF $\beta 1$ mRNA expression in the SMP8-IGF-I group. Moreover, Col $\alpha 1$ (I) mRNA abundance at 72 hours was reduced in SMP8-IGF-I mice compared with wild type controls.

Conclusions: Targeted overexpression of IGF-I by activated HSCs restricts their activation, attenuates fibrogenesis, and accelarates liver regeneration. These effects appear to be mediated in part by upregulation of HGF and downregulation of TGF $\beta 1$. The data indicate that IGF-I can modulate the cytokine response to liver injury facilitating regeneration and reducing fibrosis.
A ctivation of hepatic stellate cells (HSCs), the main producers of liver collagen, involves induction of smooth muscle alpha actin ( $\alpha$ SMA) and conversion from quiescent to proliferative, collagen expressing phenotype. ${ }^{1}$ A number of recent studies have focused attention on role of insulin-like growth factor I (IGF-I) in liver disease and HSC biology. In normal liver, IGF-I is synthesised at high levels in hepatocytes and in multiple non-parenchymal cell types ${ }^{2}$ including HSCs. ${ }^{3}$ Normal hepatocytes express 5-20 fold higher levels of IGF-I than non-parenchymal cells, ${ }^{2}$ and hepatocyte derived IGF-I is the major source of circulating IGF-I. ${ }^{5}$ Circulating IGF-I mediates growth of multiple tissues but appears to have little effect on growth of normal liver because normal hepatocytes express few IGF-I receptors. ${ }^{2}{ }^{6}$ During chronic liver disease, serum IGF-I levels are decreased and provide a useful index of hepatocellular dysfunction and impaired nutritional status. ${ }^{13}$ Prior studies in a rat model of chronic, $\mathrm{CCl}_{4}$ induced liver cirrhosis indicate that systemic administration of IGF-I improves nutritional status and liver function $^{7}$ and reduces oxidative damage and fibrosis. ${ }^{8}$

Hepatic stellate cells are known targets for IGF-I action. In cultured HSCs, IGF-I increases proliferation ${ }^{34-14}$ and collagen synthesis, ${ }^{8}$ providing indirect evidence that IGF-I could play a role in expansion of activated HSCs and in liver fibrosis. Quiescent HSCs, however, are continuously exposed to high local concentrations of IGF-I in normal liver and, yet, do not proliferate despite expression of high levels of type 1 IGF receptor (IGFIR). ${ }^{45}$ In addition, IGF-I stimulates production of hepatocyte growth factor (HGF) in hepatic stellate cells. ${ }^{16}{ }^{17} \mathrm{HGF}$ is not only a potent mitogen for hepatocytes ${ }^{18}$ but also appears to limit liver fibrosis in vivo. ${ }^{19}$ This suggests that IGF-I could indirectly act on HSC to stimulate the production of HGF which in turn could protect hepatocytes from injury or promote hepatocellular regeneration. Hence, the biological role of IGF-1 in the damaged liver has not yet been well defined and present concepts are mainly based on in vitro evidence.

It has been shown that HSCs can affect the rate of hepatocyte regeneration by regulating extracellular matrix (ECM) composition. ${ }^{1}$ Also, transforming growth factor beta 1 (TGF $\beta 1$ ), a major stimulus of ECM production in HSCs, ${ }^{1}$ has an inhibitory effect on replication of hepatocytes. ${ }^{20}$ Recent studies have demonstrated that interruption of TGF $\beta 1$ signalling improves liver fibrosis ${ }^{21} 22$ and stimulates liver regeneration, ${ }^{22}$ indicating that TGF $\beta 1$ strongly influences the biology of both HSCs and hepatocytes.

In this study we used transgenic mice (SMP8-IGF-I TG) in which the $\alpha$ SMA promoter drives the expression of rat IGF-I $\mathrm{CDNA}^{23}$ as a model to assess the role of HSC derived IGF-I on

Abbreviations: $28 \mathrm{~s}, 28$ ribosomal subunit; $\alpha \mathrm{SMA}$, smooth muscle $\alpha$ actin; ALT, alanine aminotransferase; AST, aspartate aminotransferase; $\mathrm{BrdU}$, bromodeoxyuridine; $\mathrm{CCl}_{4}$, carbon tetrachloride; cDNA, complementary DNA; Col $\alpha 1$ (I), procollagen $\alpha 1$ (I); ECM, extracellular matrix; HGF, hepatocyte growth factor; HSCs, hepatic stellate cells; IGFI, insulin-like growth factor I; IGFIR, IGF-I receptor 1; mRNA, messenger RNA; RT-PCR, reverse transcription polymerase chain reaction; TG, transgenic mice; TGF $\beta 1$, transforming growth factor beta 1; UT, untranslated region; WT, wild type mice. 
liver responses to acute $\mathrm{CCl}_{4}$ induced injury in vivo. In this mouse, the SMP8-IGF transgene is not detectable in normal liver, ${ }^{23}$ presumably because $\alpha$ SMA positive cells are scarce. We hypothesised that activation of HSCs by $\mathrm{CCl}_{4}$ would induce expression of the SMP8-IGF-I transgene in the activated HSCs and would allow us to define the effects of HSC derived IGF-I on acute liver damage and repair in vivo.

\section{METHODS}

Animals

SMP8-IGF-I transgenic (TG) mice were derived as previously described. ${ }^{23}$ The SMP8-IGF-I TG mice have germline integration of a transgene composed of the murine $\alpha \mathrm{SMA}$ promoter linked to a full length rat IGF-I cDNA. Hemizygous SMP8IGF-I TG males, on the FVB-N genetic background, were bred with FVB-N WT females (Jackson Laboratories, West Grove, PA, USA) to derive TG and WT mice for analyses. Study protocols were in full compliance with NIH guidelines for humane animal care.

\section{$\mathrm{CCl}_{4}$ treatment}

Ether sedated, 50-60 day old, sex matched TG and WT littermates were given either a single dose of $\mathrm{CCl}_{4}$ (Sigma, St Louis, MO, USA) or the same dose of corn oil by gavage ( $3.5 \mathrm{ml} / \mathrm{kg}$ of body weight in a 1:1 mixture with corn oil)..$^{24}$ In an initial study, mice were killed at 72 hours after $\mathrm{CCl}_{4}$, a time when previous studies have established full activation of HSCs in the mouse. ${ }^{25}$ In a follow up experiment, mice were killed at 3, 8, 12, 24, 48, or 72 hours after $\mathrm{CCl}_{4}$ or vehicle treatment. In this study, bromodeoxyuridine (BrdU; Sigma) was given as a single intraperitoneal injection $(120 \mathrm{mg} / \mathrm{kg})$ at 90 minutes before sacrifice. Mice were anaesthetised with Pentobarbital (Veterinary Laboratories Inc, Lanefa, KS, USA) and killed by exsanguination.

\section{IGF-I radioimmunoassay}

Plasma IGF-I concentration was measured by radioimmunoassay after removal of IGF binding proteins by C18 cartridge chromatography (Sep-Pak; Waters, Milford, MA, USA) as previously described. ${ }^{26}$

\section{Liver enzymes}

Alanine aminotransferase (ALT) and aspartate aminotransferase (AST) levels were measured using standard clinical automatic analyser (Hitachi 736).

\section{RNA extraction and analyses}

Liver RNA was extracted by a guanidine thiocyanate homogenisation, cesium chloride sedimentation method as detailed in Lund et al. ${ }^{27} 20 \mu \mathrm{g}$ of total RNA was analysed by northern blot hybridisation using a ${ }^{32} \mathrm{P}$-labelled (Amersham, Arlington Heights, IL, USA) antisense RNA probe complementary to rat IGF- $\mathrm{I}^{28}$ and a transgene specific RNA probe complementary to the SV40 3' untranslated region present within the SMP8-IGF-I transgene product. ${ }^{23}$ A mouse PL7 cRNA, encoding a ribosomal protein, was used as a control for RNA loading.

\section{Protein isolation and western blot}

Frozen liver samples were homogenised in $10 \mathrm{mM}$ Tris buffer ( $\mathrm{pH}$ 7.4) containing a cocktail of protease inhibitors (Sigma). HSC were lysed in $10 \mathrm{mM}$ Hepes buffer ( $\mathrm{pH}$ 7.9) also containing a protease inhibitor cocktail. Protein concentration was determined using the Bio-Rad Protein Assay (Bio-Rad Laboratories, Hercules, CA, USA). Extracts corresponding to $50 \mu \mathrm{g}$ of protein were separated on $12 \%$ nondenaturing SDS polyacrylamide gels and transferred to PVDF membranes (Immobilon-P; Millipore, Bedford, MA, USA), as previously described. ${ }^{29}$ Filters were blocked in $10 \%$ non-fat dry milk in TBS-T (20 mM Tris- $\mathrm{HCl} \mathrm{pH} 7.6,137 \mathrm{mM} \mathrm{NaCl}$ and $1 \%$ Tween) before incubation with primary antibodies in $5 \%$ milk in TBS-T, for 60 minutes at room temperature. After washing, membranes were incubated with HRP conjugated secondary antibodies (Jackson Immuno Research Laboratories, West Grove, PA, USA), and developed using enhanced chemiluminescence light (ECL) detection kit (Amersham Biosciences, Piscataway, NY, USA). Primary antibodies used at 1:100 dilution were mouse monoclonal antibody to SSMA (Clone A4; Dako, Carpinteria, CA, USA), and to BCL-xL (Santa Cruz Biotechnology, Santa Cruz, CA, USA), and polyclonal antibodies to HGF (R\&D Systems, Minneapolis, MN, USA) and IGF-I (Santa Cruz Biotechnology). A policlonal antibody against tubulin (Santa Cruz Biotechnology) was used as a protein loading control.

\section{Immunohistochemistry}

Formalin fixed, paraffin embedded liver blocks were sectioned at $6 \mu \mathrm{m}$ and stained with haematoxylin and eosin to evaluate morphology or with Masson's trichrome and Sirius red to detect collagen deposition. Immunohistochemistry to localise aSMA and BrdU was performed as previously described..$^{29}$

\section{Scoring of liver necrosis}

Liver necrosis was graded on coded haematoxylin and eosin stained sections by an experienced pathologist blinded to treatment groups. Scoring was as follows: grade O, no visible necrosis; grade I, focal necrosis of less than $25 \%$ of the liver lobule area; grade II, confluent centrilobular necrosis of 25-50\%; grade III, necrosis of $50-75 \%$; grade IV, necrosis of more than $75 \%$ of the liver lobule ${ }^{30}$

\section{Isolation and culture of HSCs}

HSCs from untreated TG and WT mice were isolated and purified as described previously. ${ }^{25}$ HSCs were cultured in Dulbecco's modified Eagle's medium containing $10 \%$ fetal serum, $100 \mathrm{IU} / \mathrm{ml}$ penicillin, and $100 \mu \mathrm{g} / \mathrm{ml}$ streptomycin. HSCs were plated out at a density of $10^{6} \mathrm{cells} / \mathrm{cm}^{2}$. Quiescent (newly isolated) and activated (day 14 in culture) HSCs were studied. Total RNA from cultured HSCs was prepared using TRI Reagent (Molecular Research Center, Cincinnati, OH, USA) according to the manufacturer's instructions.

\section{RT-PCR}

Expression of the transgene in cultured HSC was measured using standard RT-PCR techniques. $1 \mu \mathrm{g}$ of liver or HSC derived total RNA was reverse transcribed to complementary DNA (cDNA) using oligo(dT) and avian myeloblastosis virus reverse transcriptase (Promega, Madison, WI, USA). The sequence of a sense primer corresponding to $\alpha$ SMA $5^{\prime}$ UT and an antisense primer corresponding to SV40 $3^{\prime}$ UT of the SMP8-IGF-I transgene, as well as specific primers used to detect $\beta$-actin, are listed in table 1 . Amplification reactions were carried out as previously described ${ }^{31}$ using the GeneAmp PCR System 2400 (Perkin-Elmer, Norwalk, CT, USA).

Real-time RT-PCR was also performed to quantify expression of the mRNAs of procollagen $\alpha \mathrm{l}(\mathrm{I})$ (Col $\alpha \mathrm{l}(\mathrm{I})$ ), fibronectin, transforming growth factor beta l (TGF $\beta 1$ ), and the 28 ribosomal subunit (28s) using specific, intron spanning, primers to avoid co-amplification of genomic DNA (table 1). For real-time quantitative RT-PCR, reverse transcription of total liver RNA to cDNA was done at $42^{\circ} \mathrm{C}$ for one hour using random primers (Boehringer Ingelheim, Germany) and RTase (Gibco, Grand Island, NY, USA). During PCR amplification, the cDNA was incubated with a mix containing SYBR Green I, a dye specific for double stranded DNA (LightCycler-FastStart DNA Master SYBR Green I; Roche Diagnostics, Barcelona, Spain). Amplification 


\begin{tabular}{|c|c|c|}
\hline mRNA & & Oligomers \\
\hline \multirow{2}{*}{ SMP8-IGF-I } & Sense & 5'-GTG GCT TCT AGT GCT GAC G-3' \\
\hline & Antisense & $5^{\prime}$-CCA CTC AGG CGT ATC AGT G-3' \\
\hline \multirow[t]{2}{*}{ TGF $\beta 1$} & Sense & 5'-GAG TGG TाT GT TGA GAT GT-3' \\
\hline & Antisense & 5'-GGT TCG TGC ATC CAT TTC CA-3' \\
\hline \multirow[t]{2}{*}{$\operatorname{Col} \alpha 1(I)$} & Sense & 5'-GCA AAG AGT AGT CTA CAT GTC TAG-3' \\
\hline & Antisense & $5^{\prime}$-CCT ACA TCT TCT GAG TाT GG-3' \\
\hline Fibronectin & $\begin{array}{l}\text { Sense } \\
\text { Antisense }\end{array}$ & $\begin{array}{l}\text { 5'-TGT GAC AAC TGC CGT AGA CC-3' } \\
5^{\prime}-\text {-GAC CAA CTG TCA CCA IGG AGG-3' }\end{array}$ \\
\hline \multirow[t]{2}{*}{$\beta$-actin } & Sense & 5'-GTG ACG AGG CCC AGA GCA AGA G-3' \\
\hline & Antisense & 5'-AGG GGC CGG ACT CAT CGT-3' \\
\hline \multirow[t]{2}{*}{$28 s$} & Sense & 5'-AGA AGG GCA AAA GCT CGC TT-3' \\
\hline & Antisense & 5'-AGC AGG ATT ACC ATG GCA AC-3' \\
\hline
\end{tabular}

conditions using a thermocycler (LightCycler; Roche Molecular Biochemicals) were one step denaturation for 10 minutes at $95^{\circ} \mathrm{C}$, followed by multiple cycles of denaturation for 15 seconds at $95^{\circ} \mathrm{C}$, annealing for five seconds at $61{ }^{\circ} \mathrm{C}$, and extension for 13 seconds at $72^{\circ} \mathrm{C}$. The number of cycles were: 26, 39, and 44 for 28s, Col $\alpha \mathrm{l}(\mathrm{I})$, and TGF $\beta 1$, respectively. The specification of each PCR product was established based on its melting temperatures (LightCycler software version 3.39; Roche Molecular Biochemicals, Indianapolis, IN, USA), and appropriate size was verified on agarose gels. To prepare standards, PCR generated fragments were isolated from agarose gels, purified (GeneClean II; Q-Biogene, Carlsbad, CA, USA), cloned into the pGEM T-Easy vector (Promega, Madison, WI, USA) and sequenced (ABI PRISM 310 Genetic Analyzer; Perkin Elmer, USA). Standard curves were generated from serial dilutions of control linearised plasmids to obtain relative quantitation. Results are presented as ratios of the relative concentrations of $\operatorname{Col} \alpha \mathrm{l}(\mathrm{I})$ and TGF $\beta 1$ to the $28 \mathrm{~s}$ values.

\section{Statistical analyses}

Two way ANOVA was used to test for significance of effects of the transgene (WT $v$ TG) and $\mathrm{CCl}_{4}$ treatment, and interactions between transgene and treatment which indicate an effect of transgene on reponses to $\mathrm{CCl}_{4}$. Post hoc, pairwise comparisons were performed using Duncan's test. MannWhitney U test for non-parametric inference was used when appropriate, as indicated in the text.

\section{RESULTS}

\section{Induction of SMP8-IGF-I mRNA}

In the liver of TG mice the expression of SMP8-IGF-I transgene, as assessed by RT-PCR, occurred as soon as eight hours after $\mathrm{CCl}_{4}$ administration and tended to increase along the 72 hours of the study period (fig 1A). Northern blot analysis of liver samples obtained from WT and TG mice 72 hours after vehicle or $\mathrm{CCl}_{4}$ administration showed that the induction of the transgene occurred only in TG mice that received $\mathrm{CCl}_{4}$ (fig $1 \mathrm{~B}$ ). To confirm that the transgene is specifically expressed in activated HSCs, we examined transgene expression by RT-PCR in HSCs isolated from WT and TG mice. HSCs were examined in quiescence and after 14 days of culture on plastic to induce activation. ${ }^{25}{ }^{32}$ We observed that SMP8-IGF-I mRNA was detected only in activated TG HSCs (fig IC).

Assays of plasma IGF-I revealed a significant $(\mathrm{p}<0.01)$ decline in circulating IGF-I concentrations in both WT and TG mice at 24 hours after $\mathrm{CCl}_{4}$, but levels returned to normal by 72 hours (table 2 ). At this time point, western blot for IGF-I protein in the injured liver showed that the levels of this growth factor was more intense in TG mice than in WT animals (fig 1D), indicating that under conditions of liver
A

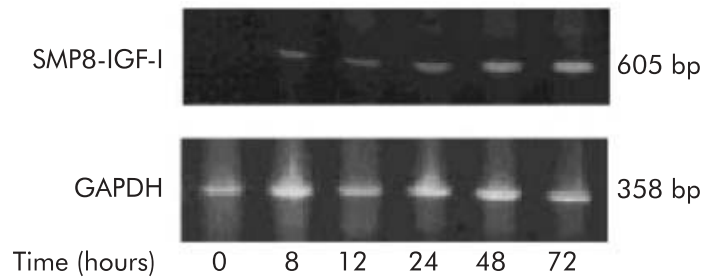

B

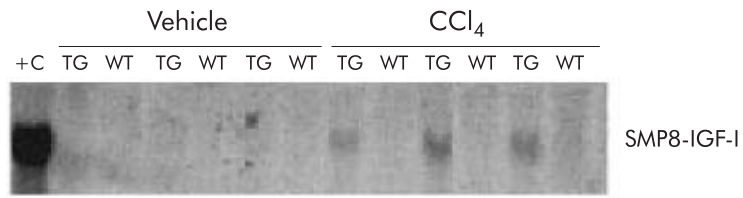

C
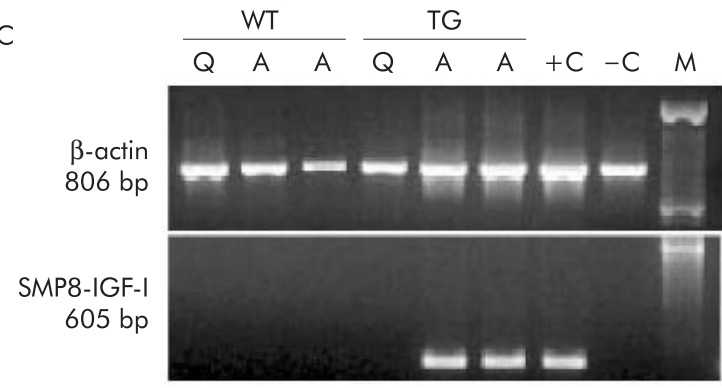

D

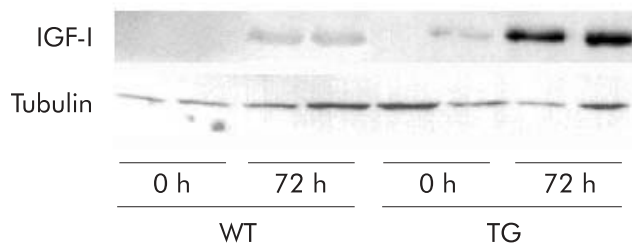

Figure 1 (A) Time course of liver expression of SMP8-IGF-I transgene in TG mice after $\mathrm{CCl}_{4}$ treatment, measured by RT-PCR. (B)

Autoradiogram of a northern blot of liver RNA probed with a transgene specific probe. Total RNA was extracted from the livers of six WT and six TG mice at 72 hours after administration of vehicle or $\mathrm{CCl}_{4}$, as described in Methods. $20 \mu \mathrm{g}$ of total RNA from small intestine (a site of strong transgene expression in smooth muscle cells) of TG mice was used as a positive control (+C). (C) RT-PCR products obtained with oligomers specific for the SMP8-IGF-I transgene and control $\beta$-actin. RT-PCR was performed on RNA isolated from quiescent (Q) or activated (A) HSCs. HSCs were activated by culture during 14 days on a plastic surface. HSCs isolated from three WT and three TG mice were pooled for extraction of RNA used for RT-PCR. +C, RT-PCR product from total RNA from small intestine of SMP8-IGF-I TG mouse; $-C$, negative control; $M$, markers. (D) Representative western blot of IGF-I in liver tissue of WT and $\mathrm{TG}$ mice at $\mathrm{O} \mathrm{h}$ and $72 \mathrm{~h}$ after $\mathrm{CCl}_{4}$. Tubulin expression was used as loading protein control.

damage the hepatic production of IGF-I is higher in the former group of animals.

\section{Liver function and morphology}

The livers of WT or TG mice receiving vehicle were histologically unremarkable. At 24 and 48 hours after $\mathrm{CCl}_{4}$ administration the typical centrilobular hepatocellular necrosis induced by this compound could be seen in both groups of animals (fig 2). ${ }^{33}{ }^{34}$ However, at 72 hours the liver lesion was largely resolved in TG mice while significant necrosis could still be observed in WT animals (fig 2). Thus, at this time point six out of eight WT mice showed severe hepatic necrosis (grade III) and the other two had moderate necrosis (grade II) while among TG mice six out of eight had virtually no 
Table 2 Plasma IGF-I concentration at 24 and 72 hours after intragastric administration of $\mathrm{CCl}_{4}$

\begin{tabular}{llll}
\hline & Vehicle & $\mathbf{2 4}$ hours & $\mathbf{7 2}$ hours \\
\hline WT & $417.7(13.7)$ & $226.6(57.8)^{*}$ & $408.3(90.1)$ \\
SMP8-IGF-I TG & $422.3(7.8)$ & $227.0(48.1)^{*}$ & $426.4(51.2)$ \\
\hline
\end{tabular}

Data represent the mean (SEM) obtained from three mice in each group. Two way ANOVA revealed significant effect of $\mathrm{CCl}_{4}$ treatment on the concentrations of circulating IGF-I at 24 hours $(p<0.01)$, but no effect of genotype. *Significantly different from vehicle treated mice.

necrosis and other two exhibited necrosis of moderate degree (grade II).

In agreement with these histological findings, serum biochemistry demonstrated a dramatic increase in transaminase levels $(>1000 \mathrm{IU} / \mathrm{l})$ at 24 hours after $\mathrm{CCl}_{4}$ ingestion in the two groups of animals, but recovery from hepatic damage was more rapid in TG mice, which showed at 48 and 72 hours values of serum transaminases significantly lower than those found in WT littermates (table 3).

\section{Liver regeneration}

In order to label proliferating cells, BrdU was administered 90 minutes before sacrifice in animals examined at 24, 48, and 72 hours after $\mathrm{CCl}_{4}$ treatment (fig 3). In both WT and TG animals, BrdU positive cells were very rarely encountered at 24 hours after injury. At 48 hours we observed an intense regeneration wave in TG mice which showed a frequency of BrdU labelled hepatocytes significantly higher than the WT littermates (218 (31) v 137 (7) positive nuclei per high power field, $\mathrm{p}<0.05)$. At 72 hours, when the healing was almost complete, the number of BrdU positive nuclei started declining in TG mice (103 (23)), while it still was on the rise in WT animals (182 (14)). These data indicate the occurrence of an accelerated hepatocyte regeneration in TG mice, which takes place with an anticipation of about 24 hours with respect WT littermates.

The transgenic IGF-I could stimulate liver regeneration either directly or through other factors involved in the regulation of hepatocyte proliferation. Mature HGF protein, a complete mitogen for hepatocytes, ${ }^{18}$ can be detected in the liver as early as six hours after $\mathrm{CCl}_{4}{ }^{35}$ and reaches its maximal values at 24 hours. ${ }^{4}{ }^{14}$ Using western blot analysis of livers at 24 hours after $\mathrm{CCl}_{4}$ administration we found that the hepatic
Table 3 Serum levels of AST and ALT in wild type and SMP8-IGF-I mice after $\mathrm{CCl}_{4}$ administration

\begin{tabular}{lllll}
\hline & 0 hours & $\mathbf{2 4}$ hours & $\mathbf{4 8}$ hours & $\mathbf{7 2}$ hours \\
\hline AST & & & & \\
WT & $20(2)$ & $32580(1957)$ & $8087(487)$ & $2255(366)$ \\
SMP8-IGF-I TG & $21(6)$ & $24020(4951)$ & $2507(158)^{*}$ & $1167(479)^{*}$ \\
ALT & 0 hours & 24 hours & 48 hours & 72 hours \\
WT & $29(8)$ & $54600(1693)$ & $7623(1051)$ & $1880(253)$ \\
SMP8-IGF-I TG & $33(7)$ & $42100(3864)$ & $4780(501)^{*}$ & $520(178)$
\end{tabular}

Values are expressed as IU/I and represent the mean (SEM) obtained from three to six mice in each group. ${ }^{*} p<0.05$ compared with the respective group of WT mice.

Figure 3 Immunohistochemical staining of the liver of WT and TG mice following $\mathrm{CCl}_{4}$ treatment. Ninety minutes before sacrifice, at the times indicated in the figure, mice received intraperitoneal injection of $\mathrm{BrdU}$ to visualise proliferating cells. Livers were harvested, processed, and stained for BrdU as described in Methods. Representative

photomicrographs are shown; arrows show positive nuclei. Scale bar $=200 \mu \mathrm{m}$.

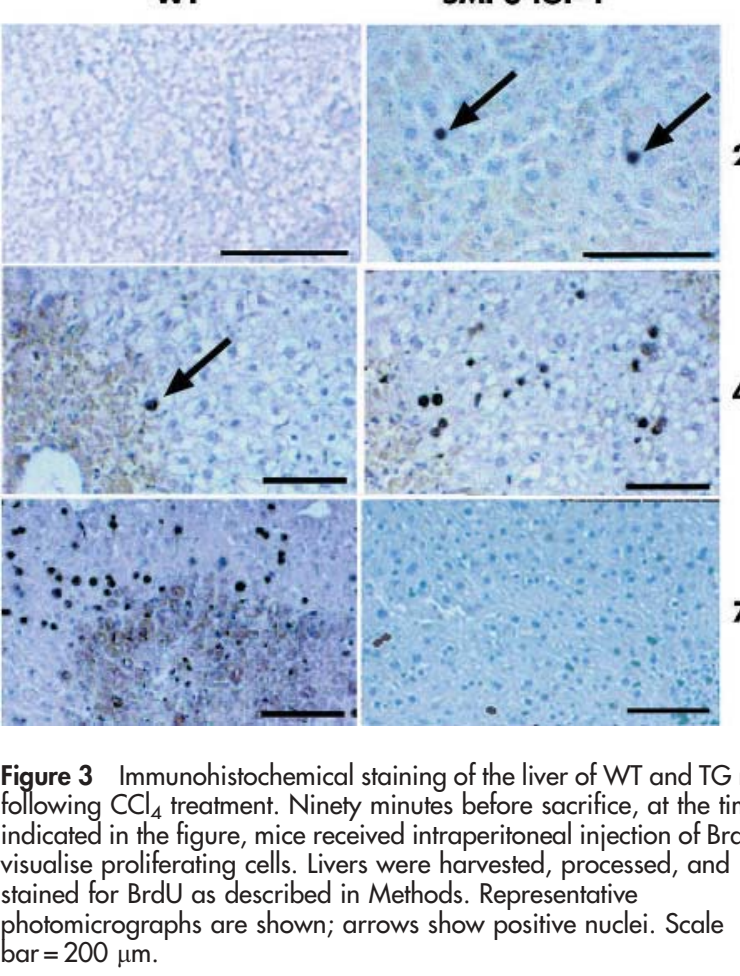

SMP8-IGF-1

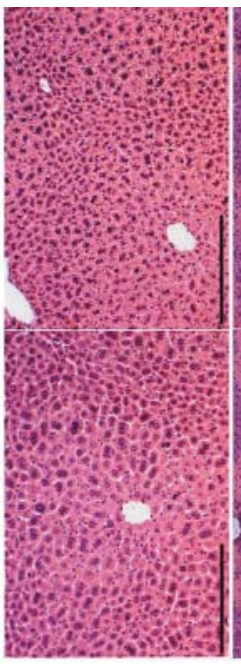

Vehicle

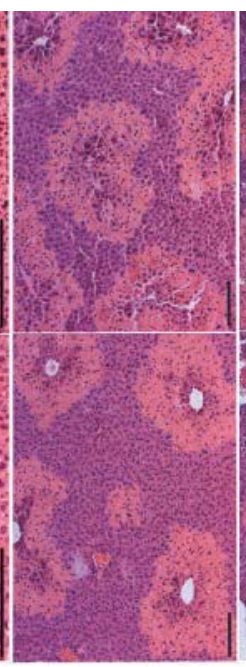

$24 \mathrm{~h}$

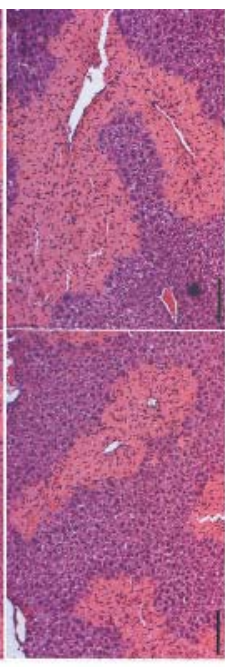

$48 h$

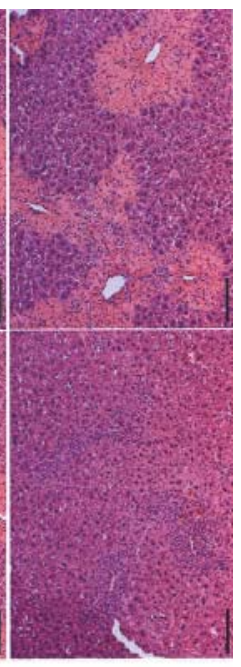

$72 \mathrm{~h}$

Figure 2 Liver morphology in WT and SMP8-IGF-I TG mice treated with vehicle and after $\mathrm{CCl}_{4}$ treatment. Livers were harvested at 24,48 , or 72 hours after intragastric administration of vehicle or $\mathrm{CCl}_{4}$. Portions of the liver were fixed, sectioned, and stained with haematoxylin and eosin. Representative photomicrographs from eight mice per group are shown. Scale bar $=200 \mu \mathrm{m}$. 
levels of HGF were higher in TG mice than in WT animals (fig 4A and B). The levels of HGF in hepatic tissue still remained higher in TG than in WT mice at 72 hours after the toxic challenge (data not shown). In order to determine whether the increased production of HGF might be derived from enhanced production of this factor by activated transgenic HSC, we analysed by western blot the production of HGF in extracts of transgenic and wild type HSC in a quiescent status or after activation by culturing during 14 days. As shown in figure 4C, we found that $\mathrm{HGF}$ was produced only by activated TG HSC, but not by WT HSC, nor by quiescent HSC. These data show that transgenic IGF-I may act autocrine/paracrine fashion to activate HGF production in HSC.

High levels of TGF $\beta 1$ inhibit liver regeneration ${ }^{20}$ whereas low levels have been shown to have a permissive effect on hepatocyte replication. ${ }^{36}{ }^{37}$ In our study we found that compared with WT, TG animals tended to express lower levels of TGF $\beta 1$ mRNA during the whole study period, the differences being statistically significant $(\mathrm{p}<0.05$, Mann-Whitney U-test) at 24 hour after $\mathrm{CCl}_{4}$ administration (fig 5A). At this time point TGF $\beta 1$ mRNA expression was
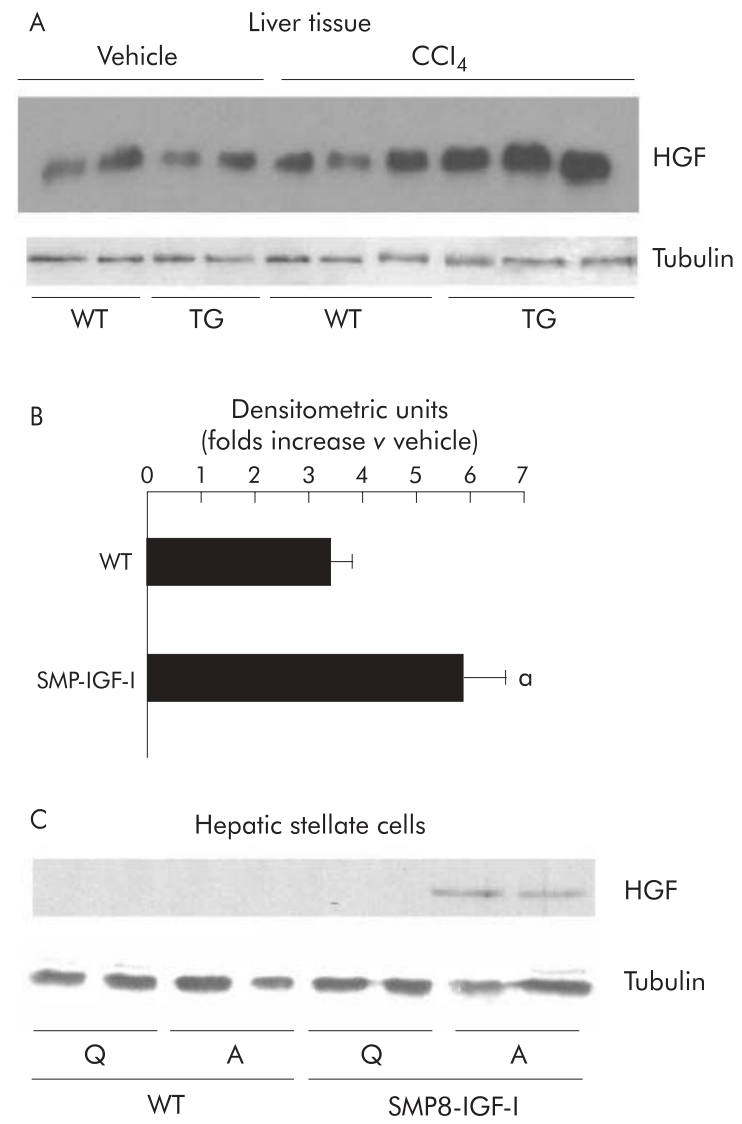

Figure 4 (A) Western blot analysis of HGF levels in the livers of $\mathrm{CCl}_{4}$ treated WT and SMP8-IGF-I TG mice. Proteins were extracted, as described in Methods, from livers harvested at 24 hours following intragastric administration of vehicle or $\mathrm{CCl}_{4}$. Western blot was performed using anti-HGF polyclonal antibody, and tubulin was used as protein loading control. (B) The intensity of each band was quantified using an image analyser. Results are expressed as the ratio between the density signal in $\mathrm{CCl}_{4}$ treated mice to the density signal in vehicle treated mice set arbitrarily at 1.0. Data represent the mean (SEM) obtained from three mice per group. a: significantly different $(p<0.05)$ from WT mice (Mann-Whitney U test). (C) Representative photomicrograph of western blot analyses of HGF levels in HSC obtained from WT and SMP8-IGF-I transgenic mice, and activated by culturing during 14 days; tubulin was used as protein loading control. Q: Quiescent HSC; A: Activated HSC. increased (relative to animals that received vehicle) 5.84 (0.72) fold in WT and only 2.04 (0.47) fold in TG. TGF $\beta 1$ mRNA expression was also analysed in HSC from TG and WT mice activated by culture on plastic for 14 days. We found that HSC obtained from TG mice showed a three fold reduction in TGF $\beta 1$ mRNA expression compared with those obtained from WT mice (fig 5B). Again these observations indicate that the transgenic IGF-I can repress the synthesis of the profibrogenic cytokine TGF $\beta 1$ by HSC either directly or indirectly through stimulation of HGF production.

\section{Collagen and fibronectin expression}

Acute $\mathrm{CCl}_{4}$ induced liver injury is accompanied by transient elevation in the expression of Col $\alpha \mathrm{l}(\mathrm{I})$ mRNA. ${ }^{25}{ }^{38}$ In our study Col $\alpha \mathrm{l}(\mathrm{I})$ mRNA levels were significantly $(\mathrm{p}<0.05)$ increased in both WT and TG mice at 48 and $72 \mathrm{~h}$ after $\mathrm{CCl}_{4}$ treatment (fig 5C, left). At 72 hours, the increase in Col $\alpha \mathrm{l}(\mathrm{I})$ mRNA values (relative to mice receiving vehicle) was significantly lower $(\mathrm{p}<0.05)$ in $\mathrm{CCl}_{4}$ treated TG mice than in $\mathrm{CCl}_{4}$ treated WT littermates (fig $5 \mathrm{C}$, left). Despite upregulation of Col $\alpha \mathrm{l}(\mathrm{I})$ mRNA, no collagen accumulation in the liver in either genotype was visualised using Masson's trichrome or Sirius red stains in our model of acute $\mathrm{CCl}_{4}$ liver injury.

The expression of fibronectin, another ECM component, remained largely unchanged except at 72 hours, when its mRNA levels (relative to mice given vehicle) were significantly lower $(\mathrm{p}<0.05)$ in $\mathrm{CCl}_{4}$ treated TG animals than in WT mice that received the hepatotoxin (fig $5 \mathrm{C}$, right).

\section{Activation of HSC}

aSMA staining was negligible in the liver of WT or TG mice that received vehicle. By contrast a dramatic increase in the number of $\alpha$ SMA positive cells was present in the livers of WT mice given $\mathrm{CCl}_{4}$. Interestingly, fewer $\alpha \mathrm{SMA}$ positive cells were detected in TG mice at 72 hours after $\mathrm{CCl}_{4}$ ingestion and were located around the central vein (fig 6, top). To confirm the immunohistochemical findings, aSMA expression in the liver extracts was analysed by immunoblot. As illustrated in figure 6 (bottom), aSMA was not detectable in vehicle treated WT or TG mice whereas it was strongly induced after $\mathrm{CCl}_{4}$ administration in WT (seven out of seven) but in only one out of six TG mice examined.

Apoptosis of activated HSCs has been reported in some models during resolution of liver injury..$^{39}$ We performed TUNEL assays to determine if increased apoptosis accounted for the lower numbers of activated HSC in TG mice. No TUNEL positive HSCs were found in livers of vehicle or $\mathrm{CCl}_{4}$ treated WT or TG mice (data not shown) indicating that apoptosis of HSC is minimal in the mouse $\mathrm{CCl}_{4}$ model of acute liver injury. Furthermore, we evaluated by western blot the expression of the antiapoptotic protein BCL-xL, whose levels are usually decreased in liver damage. ${ }^{41}$ We found that the reduction induced by $\mathrm{CCl}_{4}$ at 72 hours after toxic ingestion in both genotypes was less intense in TG than in WT mice (fig 7).

\section{DISCUSSION}

In the present study transgene expression was not detectable in the normal liver of SMP8-IGF-I TG mice, despite the fact that $\alpha \mathrm{SMA}$ is present in the scant smooth muscle cells of the intrahepatic branches of the hepatic artery. A low level of transgenic expression in these structures which represent a minimal part of the hepatic mass might determine that the abundance of SMP8-IGF-I mRNA in normal transgenic liver is below the detection threshold of the PCR technique used in our study. By contrast we show that in SMP8-IGF-I TG mice the transgene is induced in the liver after $\mathrm{CCl}_{4}$ injury and in isolated HSCs upon activation, thus demonstrating that the 

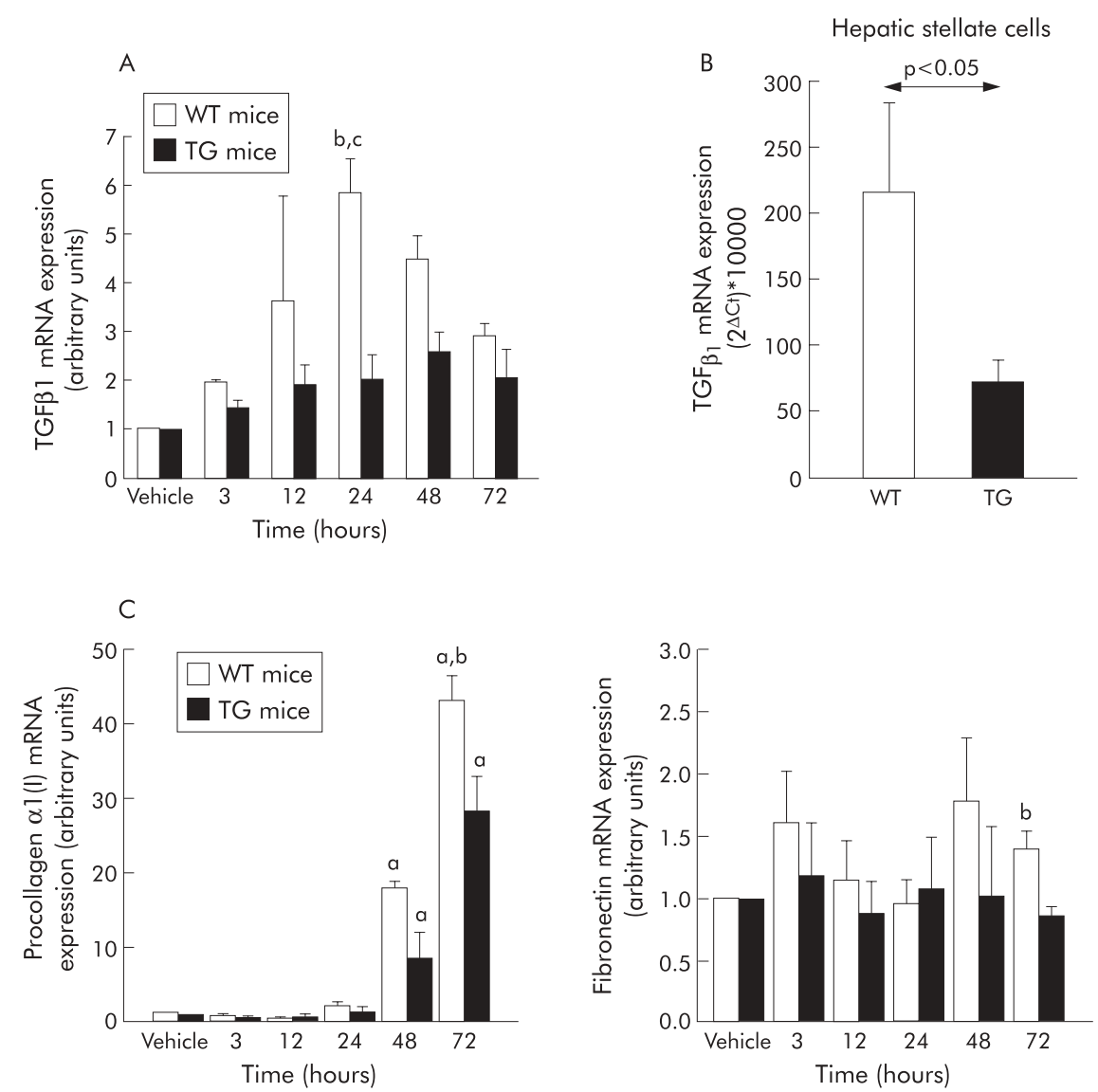

Figure 5 (A) Real-time RT-PCR analyses of TGF $\beta 1$ mRNA values in the livers of WT and SMP8-IGF-I TG mice. Livers were harvested at indicated times following treatment with vehicle or $\mathrm{CCl}_{4}$. Total RNA was extracted and processed as detailed in Methods. Following amplification, mRNA levels were

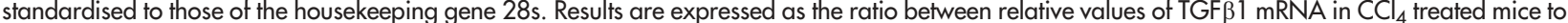
those of TGF $\beta 1$ mRNA in vehicle treated mice set arbitrarily at 1.0. Data represent the mean (SEM) from three to six mice per group analysed at each time point. b: significantly different $(p<0.01)$ from vehicle treated group; $c$ : significantly different $(p<0.05)$ from TG mice. (B) Real time RT-PCR analyses of TGF $\beta 1$ mRNA levels in HSC obtained from WT and transgenic mice, activated during 14 days in culture. Total RNA was extracted and processed as detailed in Methods. Units were calculated from the formula: $2^{\Delta \mathrm{Ct}} \times 10000$ ( $\Delta \mathrm{Ct}=$ number of cycles of housekeeping gene minus number of cycles of TGF $\beta 1$ ). Data represent the mean (SEM) from 10-12 experiments. Statistical significances are shown in the figure. (C) Real-time quantitative RT-PCR analyses of expression of procollagen $\alpha$ l (I) (left panel) and fibronectin (right panel) in the livers of WT and SMP8-IGF-I TG mice harvested at indicated time points following vehicle or $\mathrm{CCl}_{4}$ treatment (see methodological details in (A)). Data represent the mean (SEM) from three to six mice per group analysed at each time point. a: significantly different $(p<0.05)$ from vehicle-treated group; b: significantly different $(p<0.05)$ from TG mice (Mann-Whitney U test).

aSMA promoter is a useful tool to deliver expression of selected genes specifically to activated HSCs. This model allowed us to analyse the effect of HSC derived IGF-I on the liver response to injury.

Massive necrosis of hepatocytes after $\mathrm{CCl}_{4}$ ingestion is followed by a replicative response which is orchestrated by a highly complex cytokine cascade. The whole reparative process is usually completed within five days.$^{42}$ Our results show that injury induced expression of the SMP8-IGF-I gene in activated HSCs in vivo was not sufficient to clearly diminish initial damage by $\mathrm{CCl}_{4}$, but did lead to accelerated liver regeneration, improved liver morphology and biochemistry, and fewer activated HSCs by 72 hours after $\mathrm{CCl}_{4}$, indicating an effect of the transgene in the improvement of the recovery after injury. This rapid cure seems to result from stimulation of liver cell regeneration, but we cannot completely exclude the contribution of a direct or indirect effect of IGF-I on the modulation of the intensity of hepatocellular damage.

We have observed that IGF-I protein can be detected by western blot at higher levels in the liver of TG mice than in WT mice. As the concentration of circulating IGF-I is similar in WT and TG mice after injury, it seems that improved healing observed in TG mice may result from the autocrine/ paracrine effects of transgene derived IGF-I induced in HSCs upon activation.

SMP8 IGF-I-derived IGF-I could act indirectly by modulating the synthesis of other growth factors which regulate hepatocellular proliferation. We focused our attention on HGF, a complete mitogen for hepatocytes that increases transiently in the injured liver, ${ }^{18}{ }^{43}$ and TGF $\beta 1$, a known inhibitor of hepatocyte growth which is induced after $\mathrm{CCl}_{4}$ injury. ${ }^{20}$ In our study we observed, at 24 hours after injury, a more intense increase of HGF in the liver of TG mice than in WT animals. The increase in HGF expression persisted, although at lower levels at 72 hours. This finding suggests that the HSC derived IGF-I may accelerate healing at least in part by enhancing the HGF response to injury. This interpretation is supported by earlier findings demonstrating induction of HGF by IGF-I in HSCs in vitro ${ }^{16}{ }^{17}$ and by our data showing that HSC from TG mice produce more HGF upon activation than wild type HSC.

TGF $\beta 1$ is a multifunctional cytokine which on one hand activates HSCs and promotes fibrogenesis ${ }^{1}$ and on the other 

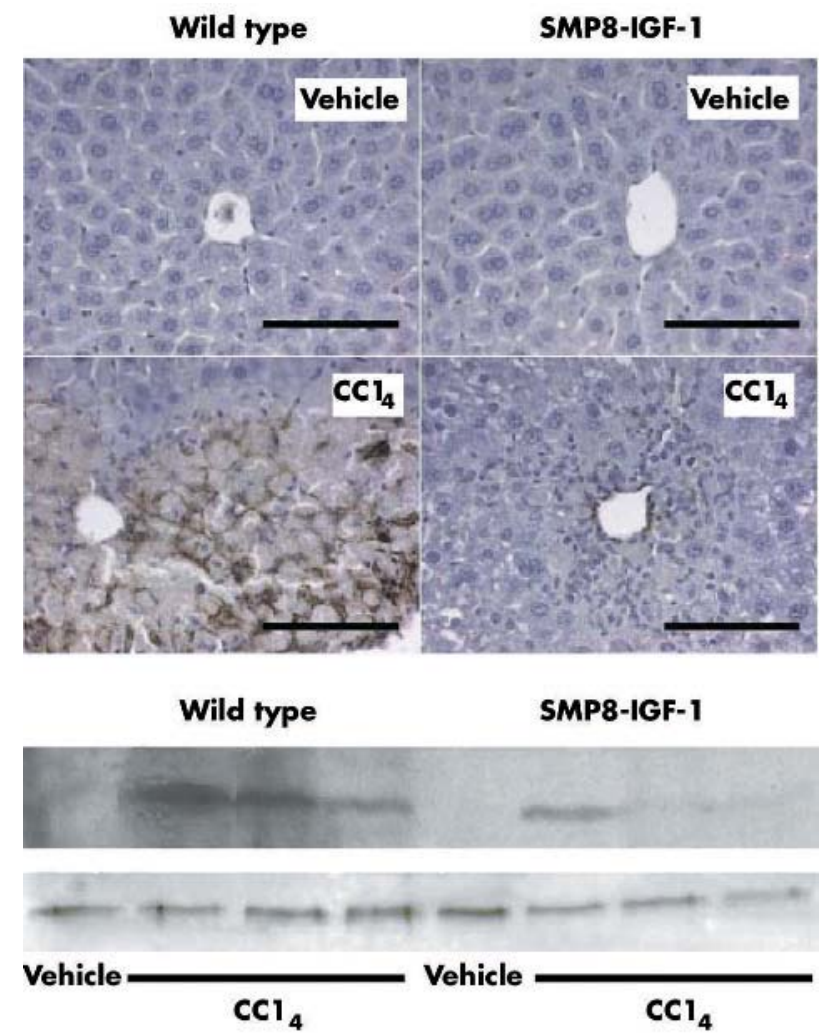

Figure 6 Top: Immunohistochemical staining of the liver with antibody specific for $\alpha$ SMA. Sections of the livers from WT and SMP8-IGF-I TG mice, harvested at 72 hours following vehicle or $\mathrm{CCl}_{4}$ treatment, were stained with anti- $\alpha$ SMA monoclonal antibody as described in Methods. Representative photomicrographs from eight mice per group are shown. Scale bar $=200 \mu \mathrm{m}$. Bottom: Representative western blot of analyses of aSMA (46 kDa) levels in the livers obtained from the same experiment. Tubulin western blot is included as a loading protein control.

hand inhibits hepatocyte proliferation. ${ }^{20}$ The observed decrease in TGF $\beta 1$ in TG mice (fig 5) could contribute to accelerated liver regeneration ${ }^{36}{ }^{37}$ as well as to the reduction in the number of $\alpha$ SMA positive HSCs. ${ }^{21} 25$ This reduction does not appear to be due to increased apoptosis of HSC because no apoptotic HSC were detected either in WT or TG mice, and BCL-xL was more intensely expressed in TG than in WT livers (fig 7). The process of activation of HSCs involves a TGF $\beta 1$ independent initiation phase followed by TGF $\beta 1$ dependent perpetuation phase. ${ }^{25}$ The reduced number of aSMA positive HSCs found in TG mice could reflect attenuated perpetuation, consistent with the low TGF $\beta 1$ mRNA levels observed both in liver tissue and HSC in these animals. The exact mechanism of inhibition of TGF $\beta 1$ mRNA expression by IGF-I remains unknown, but could involve the ability of IGF-I to increase antioxidant activity of catalase in the liver ${ }^{44}$ or lower numbers of activated HSCs expressing TGF $\beta$.

Our results show that IGF-I induction in HSCs attenuates collagen expression during acute liver injury in TG mice. It seems likely that the decrease in collagen mRNA may result from different factors including reduced injury, enhanced production of HGF (a hepatotrophic factor known to suppress hepatic fibrogenesis ${ }^{19}$ ) and decreased TGF $\beta 1$ mRNA. In spite of increased collagen gene expression, neither WT nor TG mice showed signs of accumulation of collagen in this model of acute liver injury (data not shown) which is consistent with reports in other strains..$^{24}$

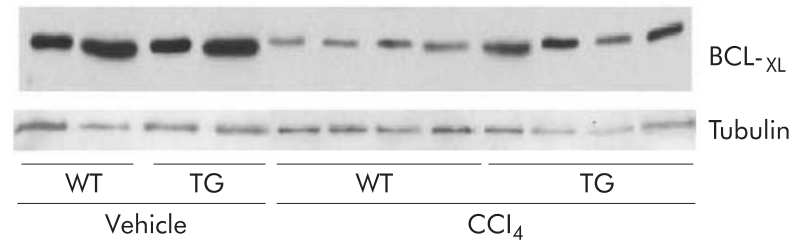

Figure 7 Representative western blot of $\mathrm{BCL}_{-\mathrm{xL}}$ levels in the livers obtained from WT and SMP8-IGF-I TG mice, harvested at 72 hours following vehicle or $\mathrm{CCl}_{4}$ treatment. Tubulin western blot is included as a loading protein control.

Although we were able to detect IGF-I by western blot in livers from TG mice after toxic challenge, we could not definitively localise SMP8-IGF-I transgene expression solely to HSCs. Attempts to localise transgene by in situ hybridisation or histochemistry proved problematic because of high non-specific binding of cRNA probes or IGF-I antibodies to necrotic tissue and because the transgene specific probe is small and has limited sensitivity. We cannot exclude that the transgene expression is induced in other cell types as well as in HSCs, such as vascular smooth muscle cells. In any case, the dramatic improvement in repair in SMP8-IGF-I TG, despite similar circulating IGF-I as in WT, indicates that the effect reflects local transgene induction in HSCs and possibly other cell types with resulting largely paracrine activities. It is also important to note that the beneficial effect of HSC derived IGF-I during acute injury does not anticipate what would be the role of HSC derived IGF-I in fibrosis associated with chronic injury. We have attempted to compare the responses of SMP8-IGF-I TG and WT to chronic $\mathrm{CCl}_{4}$ induced injury and fibrosis but this FVB strain appears resistant to fibrosis (unpublished data).

In conclusion, our study demonstrates that the SMP8 promoter is a useful tool to deliver genes of interest to activated HSCs in vitro and to injured liver and, likely, to activated HSCs in vivo. SMP8-IGF-I induction in the liver in vivo during $\mathrm{CCl}_{4}$ injury accelerates liver regeneration and this is associated with increased production of HGF, reduced expression of TGF $\beta 1$, and reduced collagen mRNA expression. Together these data support a beneficial role of HSC derived IGF-I in tissue repair after acute liver injury.

\section{ACKNOWLEDGEMENTS}

This work was facilitated by the Center for Gastrointestinal Biology and Disease (NIH grant DK-34987) and supported by NIH grants DK02402 (to JBP), DK-47769 (to PKL), Chinese Government Award (to SL), a travel grant from Echébano Foundation (to SS), and grants from Instituto Salud Carlos III C03/02, Fondo Investigaciones Sanitarias 01/0843 (to CMR-O), and Ministerio Ciencia y Tecnologia SAF 2002-0327 (to JP).

\section{Authors' affiliations \\ S Sanz, C M Rodríguez-Ortigosa, M-L Martínez-Chantar, A Pardo, J Prieto, Division of Hepatology and Gene Therapy, Clinica Universitaria and Medical School. Center for Applied Medical Research (CIMA), University of Navarra, Pamplona, Spain \\ J B Pucilowska, S Liu, P Kay Lund, D A Brenner, C Randall Fuller, Center for Gastrointestinal Biology and Disease, University of North Carolina at Chapel Hill, Chapel Hill, NC, USA \\ J B Pucilowska, S Liu, P Kay Lund, J G Simmons, Department of Cell and Molecular Physiology, University of North Carolina at Chapel Hill, NC, USA \\ D A Brenner, Department of Medicine, University of North Carolina at Chapel Hill, NC, USA \\ J A Fagin, Division of Endocrinology and Metabolism, University of Cincinnati, OH, USA}

SS and SL contributed equally to this work. 


\section{REFERENCES}

1 Friedman SL. Molecular regulation of hepatic fibrosis, an integrated cellular response to tissue injury. J Biol Chem 2000;275:2247-50.

2 Zimmermann EM, Li L, Hoyt EC, et al. Cell-specific localization of insulin-like growth factor binding protein mRNAs in rat liver. Am J Physiol 2000:278:G447-G457.

3 Pinzani M, Abboud HE, Aron DC. Secretion of insulin-like growth factor-l and binding proteins by rat liver fat-storing cells: regulatory role of platelet-derived growth factor. Endocrinology 1990;127:2343-9.

4 Scharf JG, Knittel T, Dombrowski F, et al. Characterization of the IGF axis components in isolated rat hepatic stellate cells. Hepatology 1998;27:1275-84.

5 Yakar S, Liu J-L, Stannard B, et al. Normal growth and development in the absence of hepatic insulin-like growth factor I. Proc Natl Acad Sci U S A 1999:96:7324-9.

6 Caro JF, Poulos J, Ittoop O, et al. Insulin-like growth factor I binding in hepatocytes from human liver, human hepatoma, and normal, regenerating, and fetal rat liver. J Clin Invest 1988;81:976-81.

7 Picardi A, Deoliveira AC, Muguerza B, et al. Low doses of insulin-like growth factor-l improve nitrogen retention and food efficiency in rats with early cirrhosis. J Hepatol 1997; 26:191-202.

8 Svegliati-Baroni G, Ridolfi F, Di Sario A, et al. Insulin and insulin-like growth factor-1 stimulate proliferation and type I collagen accumulation by human hepatic stellate cells: differential effects on signal transduction pathways. Hepatology 1999;29:1743-51.

9 Bachem MG, Meyer D, Schafer W, et al. The response of rat liver perisinusoidal lipocytes to polypeptide growth regulator changes with their transdifferentiation into myofibroblast-like cells in culture. J Hepatol 1993;18:40-52.

10 Gentilini A, Feliers D, Pinzani $M$, et al. Characterization and regulation of insulin-like growth factor binding proteins in human hepatic stellate cells. J Cell Physiol 1998; 174:240-50

11 Gentilini A, Marra F, Gentilini P, et al. Phosphatidylinositol-3 kinase and extracellular signal-regulated kinase mediate the chemotactic and mitogenic effects of insulin-like growth factor-l in human hepatic stellate cells. J Hepatol 2000;32:227-34.

12 Gressner AM, Brenzel A, Vossmeyer T. Hepatocyte-conditioned medium potentiates insulin-like growth factor (IGF) 1 and 2 stimulated DNA synthesis of cultured fat storing cells. Liver 1993;13:86-94.

13 Gressner AM, Lahme B, Brenzel A. Molecular dissection of the mitogenic effect of hepatocytes on cultured hepatic stellate cells. Hepatology 1995;22:1507-18.

14 Zindy $F$, Lamas $E$, Schmidt $S$, et al. Expression of insulin-like growth factor II (IGF-II) and IGF-II, IGF-I and insulin receptors mRNAs in isolated nonparenchymal rat liver cells. J Hepatol 1992;14:30-4.

15 Brenzel A, Gressner AM. Characterization of insulin-like growth factor (IGF)-Ireceptor binding sites during in vitro transformation of rat hepatic stellate cells to myofibroblasts. Eur J Clin Chem Clin Biochem 1996:34:401-9.

16 Skrtic S, Wallenius K, Gressner AM, et al. Insulin-like growth factor signaling pathways in rat hepatic stellate cells: importance for deoxyribonucleic acid synthesis and hepatocyte growth factor production. Endocrinology 1999: 140:5729-35

17 Skrtic S, Wallenius K, Ekberg S, et al. Insulin-like growth factors stimulate expression of hepatocyte growth factor but not transforming growth factor betal in cultured hepatic stellate cells. Endocrinology 1997;138:4683-9.

18 Burr AW, Toole K, Chapman C, et al. Anti-hepatocyte growth factor antibody inhibits hepatocyte proliferation during liver regeneration. J Pathol $1998 ; 185: 298-302$

19 Matsuda Y, Matsumoto K, Yamada A, et al. Preventive and therapeutic effects in rats of hepatocyte growth factor infusion on liver fibrosis/cirrhosis. Hepatology 1997;26:81-9.

20 Russell WE, Coffey RJJ, Ouellette AJ, et al. Type beta transforming growth factor reversibly inhibits the early proliferative response to partial hepatectomy in the rat. Proc Natl Acad Sci U S A 1988:85:5126-30.

21 George J, Roulot D, Koteliansky VE, et al. In vivo inhibition of rat stellate cell activation by soluble transforming growth factor beta type II receptor: a potential new therapy for hepatic fibrosis. Proc Natl Acad Sci U S A 1999:96:12719-24.
22 Ueno $\mathrm{H}$, Sakamoto T, Nakamura T, et al. A soluble transforming growth factor beta receptor expressed in muscle prevents liver fibrogenesis and dysfunction in rats. Hum Gene Ther 2000;11:33-42.

23 Wang J, Niu W, Nikiforov Y, et al. Targeted overexpression of IGF-I evokes distinct patterns of organ remodeling in smooth muscle cell tissue beds of transgenic mice. J Clin Invest 1997; 100:1425-39.

24 Shi Z, Wakil AE, Rockey DC. Strain-specific differences in mouse hepatic wound healing are mediated by divergent $\mathrm{T}$ helper cytokine responses. Proc Natl Acad Sci U S A 1997;94:10663-8.

25 Hellerbrand C, Stefanovic B, Giordano F, et al. The role of TGFß1 in initiating hepatic stellate cell activation in vivo. J Hepatol 1999;30:77-87.

26 Davenport ML, D'Ercole AJ, Underwood LE. Effect of maternal fasting on fetal growth, serum insulin-like growth factors (IGFs), and tissue IGF messenger ribonucleic acids. Endocrinology 1990;126:2062-7.

27 Lund PK, Moats-Staats BM, Hynes MA, et al. Somatomedin-C/insulin-like growth factor-I and insulin-like growth factor-II mRNAs in rat fetal and adult tissues. J Biol Chem 1986;261:14539-44.

28 Thissen JP, Pucilowska JB, Underwood LE. Differential regulation of insulin-like growth factor I (IGF-I) and IGF binding protein-1 messenger ribonucleic acids by amino acid availability and growth hormone in rat hepatocyte primary culture. Endocrinology 1994;134:1570-6.

29 Pucilowska JB, McNaughton KK, Mohapatra NK, et al. IGF-I and procollagen al(I) are coexpressed in a subset of mesenchymal cells in active Crohn's disease. Am J Physiol 2000;279:G1307-22.

30 Zhang LP, Takahara T, Yata Y, et al. Increased expression of plasminogen activator and plasminogen activator inhibitor during liver fibrogenesis of rats: role of stellate cells. J Hepatol 1999;31:703-11.

31 Simmons JG, Pucilowska JB, Lund PK. Autocrine and paracrine actions of intestinal fibroblast-derived insulin-like growth factors. Am J Physiol 1999;276:G817-27.

32 Rockey DC, Boyles JK, Gabbiani G, et al. Rat hepatic lipocytes express smooth muscle actin upon activation in vivo and in culture. J Submicrosc Cytol Pathol 1992;24:193-203.

33 Cameron GR, Karunarante WAE. Carbon tetrachloride cirrhosis in relation to liver regeneration. J Pathol Bacteriol 1936;62:1-20.

34 Smuckler EA. Structural and functional changes in acute liver injury. Environ Health Perspect 1976;15:13-25.

35 Shimizu M, Hara A, Okuno M, et al. Mechanism of retarded liver regeneration in plasminogen activator-deficient mice: impaired activation of hepatocyte growth factor after Fas-mediated massive hepatic apoptosis. Hepatology 2001;33:569-76.

36 Date M, Matsuzaki K, Matsushita M, et al. Modulation of transforming growth factor beta function in hepatocytes and hepatic stellate cells in rat liver injury. Gut 2000;46:719-24.

37 Nakamura T, Sakata R, Ueno T, et al. Inhibition of transforming growth factor beta prevents progression of liver fibrosis and enhances hepatocyte regeneration in dimethylnitrosamine-treated rats. Hepatology 2000;32:247-55.

38 Maher JJ, McGuire RF. Extracellular matrix gene expression increases preferentially in rat lipocytes and sinusoidal endothelial cells during hepatic fibrosis in vivo. J Clin Invest 1990:86:1641-8.

39 Iredale JP, Benyon RC, Pickering J, et al. Mechanisms of spontaneous resolution of rat liver fibrosis. Hepatic stellate cell apoptosis and reduced hepatic expression of metalloproteinase inhibitors. J Clin Invest 1998; 102:538-49.

40 Saile B, Knittel T, Matthes N, et al. CD95/CD95L-mediated apoptosis of the hepatic stellate cell. A mechanism terminating uncontrolled hepatic stellate cell proliferation during hepatic tissue repair. Am J Pathol 1997;151:1265-72.

41 Kovalovich K, Li W, DeAngelis R, et al. Interleukin-6 protects against Fasmediated death by establishing a critical level of anti-apoptotic hepatic proteins FLIP, Bcl-2, and Bcl-xL. J Biol Chem 2001;276:26605-13.

42 Yamada $Y$, Fausto N. Deficient liver regeneration after carbon tetrachloride injury in mice lacking type 1 but not type 2 tumor necrosis factor receptor. Am J Pathol 1998;152:1577-89.

43 Maher JJ. Cell-specific expression of hepatocyte growth factor in liver. Upregulation in sinusoidal endothelial cells after carbon tetrachloride. J Clin Invest 1993:91:2244-52.

44 Castilla-Cortázar I, García M, Muguerza B, et al. Hepatoprotective effects of insulin-like growth factor I in rats with carbon tetrachloride-induced cirrhosis. Gastroenterology 1997;113:1682-91. 